\title{
Anthropology of Outer Space: Familiar Scales, Strange Sites
}

\section{Please cite as:}

Oman-Reagan, Michael P. and Kira Turner. 2015. Call for Papers: "Anthropology of Outer Space: Familiar Scales, Strange Sites." 114th Annual Meeting of the American Anthropological Association; Denver, Colorado. 18-22 November.

\section{Call for Papers AAA 2015 - Denver, Colorado, USA}

Topic: Current interdisciplinary research in the anthropology of outer space.

Discussant: Lisa R. Messeri, PhD (Assistant Professor, University of Virginia)

Organizers: Kira Turner, PhD candidate (York University) \& Michael P. Oman-Reagan, PhD Candidate (Memorial University)

Conference: 114th American Anthropological Association Annual Meeting (November 18-22, 2015 in Denver, Colorado)

This panel aims to investigate the meanings, limits, and possibilities of expanding our anthropological fieldwork into space. At stake is an understanding of how human activity in space increasingly shapes possible human futures both on and off planet Earth. We ask: What are the constraints and potentialities of interrogating outer space in this emerging era of science, imagination, exploration, and settlement?

Planetary scientists, astronauts, and others working within the contested terrains of space science, exploration, settlement, and resource extraction are constructing diverse, sometimes conflicting, visions for human futures in space. This panel builds on anthropology's attunement to multiple scales of inquiry to investigate the complex dimensions of our emerging field sites in both space and here on Earth. Narratives of space dominance, alongside venture capitalism and the space industry, explicitly aim for the privatization and commodification of other worlds and their resources. However, today's globalizing space exploration increasingly defies familiar Cold War narratives as India, Nigeria, Indonesia, and others join the list of space faring nations. At the boundaries where our familiar everyday lives on Earth meet figurations of the alien and otherworldly in outer space, we find productive areas of inquiry at the intersections of space sciences, political economy, technosocialities, and imaginaries.

Anthropologists querying outer space are shaping theoretical, methodological, and ethnographic approaches as they break new ground and generate possibilities for this emergent field of the Anthropology of Space. Inspired by the discourses, representations, materializations, and imaginary worlds of outer space, as well as science fiction and "speculative fabulations" (e.g., Haraway 2013), this panel aims to highlight new anthropological scholarship exploring these tensions. We are interested in work examining these topics through social, environmental, historical, ontological, material, performative and other approaches, such as: 
- Space histories, scientific future imaginaries

- Embodied and anthropomorphized robotic exploration rovers

- Outer space infrastructures, analogues and extreme environments

- Space tourism, interstellar travel, multi-generational world ships

- Satellites, environment, climate change, space medicine

- Emergent methods and theories of what we could call astro-/exo-/xeno-anthropology

Accordingly, we seek papers that contribute to the emerging anthropological literature on outer space while unsettling understandings of the familiar world amidst promises and threats of uncertain futures in both strange and familiar places and spaces.

Anthropology has a history of engagements with space. In the 1970s, a series of interdisciplinary AAA symposia brought scholars together to discuss possible cultures of the future. In 1974, these organizers focused their symposium on the question of extraterrestrial communities. The resulting papers were collected in the book "Cultures Beyond the Earth: The Role of Anthropology in Outer Space" (Maruyama et al. 1975). In 2009, David Valentine, Valerie Olson, and Debbora Battaglia revived the call for anthropologists to take outer space seriously as a field site with new theoretical and methodological approaches (Valentine et al. 2009). Our discussant, Lisa Messeri, takes up this challenge in her work on the role of classification and place in space science (e.g., 2010, 2011, 2014). At the 2012 AAA meeting, anthropologists engaging with outer space presented their research in a panel entitled "Alter(native) Visions of Futures and Outer Spaces." That same year, a special collection in Anthropological Quarterly brought together work by Abou Farman, Joseph Masco, Stefan Helmreich, Götz Hoeppe, as well as Olson, Valentine, and Battaglia (Valentine et al. 2012).

The night sky inspired our ancestors as they looked up at stars, planets, and into the heart of the Milky Way while imagining their place in a universe of deities, spirits, otherworlds, and afterlives. Maya mythologies saw what we call the Milky Way as a path to the afterlife, and speculation about other worlds and extraterrestrial life dates back to the writings of Democritus (Dick 1982). Today, forty-five years after the NASA Apollo program first landed humans on Earth's moon, and 115 years after the first science fiction film "Trip to the Moon" [Le Voyage dans la Lune], we see an explosion of interest in space and space exploration. As scientific engagements extend human activity to the far reaches of our solar system, new technologies, networks, and socialities bring data and stories from these otherworldly encounters back to earth. Space faring state institutions, private corporations, and public fascination increasingly confront the familiar and the strange through both imagined and actual encounters with outer space.

To Submit: Please email a 250 word abstract to both session organizers by March 15, 2015. Please include the title of the paper, author's name, affiliation, and email. For conference requirements please see "Requirements for Section Invited and Volunteered Submissions" here: http://www.aaanet.org/meetings/Call-for-Papers.cfm

Michael P. Oman-Reagan: omanreagan@mun.ca

Kira Turner: $\underline{\text { 4turner@yorku.ca }}$ 


\section{References Cited}

Dick, Steven J.

1982 Plurality of Worlds: The Origins of the Extraterrestrial Life Debate from Democritus to

Kant. Cambridge: Cambridge University Press.

Haraway, Donna

2013 “SF: Science Fiction, Speculative Fabulation, String Figures, So Far". Ada: A Journal of

Gender, New Media, and Technology.

Maruyama, Magoroh, Arthur M. Harkins, and American Anthropological Association.

1975 Cultures beyond the Earth: The Role of Anthropology in Outer Space. New York: Vintage

Books.

Messeri, Lisa R.

2010 The Problem with Pluto Conflicting Cosmologies and the Classification of Planets. Social Studies of Science 40(2): 187-214.

2011 Placing Outer Space: An Earthly Ethnography of Other Worlds. Ph.D. Dissertation in

History, Anthropology, and Science, Technology and Society (HASTS), Massachusetts Institute of Technology.

2014 Earth as Analog: The Disciplinary Debate and Astronaut Training That Took Geology to the Moon. Astropolitics 12(2-3): 196-209.

Valentine, David, Valerie A. Olson, and Debbora Battaglia (eds).

2009 Encountering the Future: Anthropology and Outer Space. Anthropology News 50(9): 1115.

2012 Extreme: Humans at Home in the Cosmos. Special Collection, Anthropological Quarterly $85(4)$. 